\title{
Organización interna y orientación filosófica en la biblioteca de Hernando Colón
}

\author{
Internal organization and philosophical orientation in the Ferdinand Columbus's Library
}

\author{
Diego GaRcia Cañas \\ Facultad de Comunicación y Documentación, Universidad de Murcia, Campus Universitario de Espinardo s/n, \\ Murcia (España), diego.garciac@um.es
}

\begin{abstract}
Resumen
En este artículo se examina un proyecto de gran interés para la organización del conocimiento como lo fue la biblioteca creada por Hernando Colón en el siglo XVI. Por sus recursos, por su extensión y por su capacidad de expandirse revela características inusuales en su tiempo, anticipando en gran medida nuestros actuales sistemas documentales. Presentamos primeramente sus repertorios bibliográficos como un conjunto de catálogos interconectados y a partir de esto consideramos una base filosófica que nos ayuda a encontrar un sentido y una orientación general para entender el verdadero alcance de la empresa hernandina. Relacionamos la organización bibliotecaria de Hernando Colón con Erasmo, Ramon Llull y sobre todo con la visión del universo de Nicolás de Cusa, pero también con la cartografía tardomedieval; y finalmente se destaca aquí la importancia histórica de este proyecto que nos sitúa en el origen mismo de la actividad documental, vinculándolo por ello con Paul Otlet y buscando un nexo común que permita unir a ambos con el pensamiento utópico de Francis Bacon.
\end{abstract}

Palabras clave: Colón, Hernando. Biblioteca Colombina. Renacimiento. Repertorios bibliográficos. Organización del conocimiento. Filosofía. Universalidad. Cusa, Nicolás de. Otlet, Paul. Bacon, Francis.

\section{Introducción}

La figura de don Hernando Colón, uno de los hijos del primer Almirante de las Indias, debió de resultar un enigma para sus propios contemporáneos, tal como nos señala el filólogo y medievalista Klaus Wagner (2000, p.65). Amplios intereses de estudio y una fuerte curiosidad intelectual hicieron de este hombre polifacético un humanista, un lexicógrafo, un buen conocedor de las ciencias y de las artes en su conjunto; pero también un cartógrafo y un navegante, aunque entre todas sus actividades destacaría singularmente por haber sido un gran bibliófilo como lo será no mucho después Conrad Gesner. A diferencia del bibliógrafo suizo, la pasión de Hernando Colón por coleccionar libros le llevaría no sólo a crear un registro bibliográfico de miles de obras sino una biblioteca de dimensiones descomunales que llegará a albergar unos 15.300 libros, lo que

\begin{abstract}
This work examines a project of great interest for knowledge organization as it was the library created by Hernando Colón in the XVI century. For its resources, its extension and its ability to expand itself reveals some unusual characteristics for that period of time, foreseeing to a large extent our current documentation systems. We firstly present its bibliographic repertoire as a group of interconnected catalogues and from this we consider a philosophical base which help us to find a meaning and a general orientation to understand the real effect for the hernandina enterprise. We relate the bibliographic organization of Hernando Colón to Erasmus, Raymond Lull and mainly to the view of the universe of Nicholas of Cusa, but also with the late Middle Ages cartography; and finally, it is highlighted here the historical importance of this project that place ourselves in the beginning of the documentary activity, connecting it with Paul Otlet and searching for a common nexus that allows to link both with the utopian thinking of Francis Bacon.
\end{abstract}

Keywords: Colón, Hernando. Biblioteca Colombina. Renaissance. Bibliographic repertoires. Knowledge organization. Philosophy. Universality. Cusa, Nicholas of. Otlet, Paul. Bacon, Francis.

con creces la convierte en la colección más extensa y variada de su tiempo. La Biblioteca Colombina o también llamada Biblioteca Hernandina o Fernandina (ca. 1509-1539), pues es así como su propietario quería que se la conociera, fue la obra de una mente con amplitud de miras que supo anticipar una visión de universalidad liberada de prejuicios ideológicos y religiosos y que se interesó en el conocimiento en toda su extensión y variedad; esta biblioteca habría de ser reconocida por ello como una verdadera "biblioteca universal", toda una hazaña del Renacimiento que en sus pretensiones de trascender fronteras conserva mucho del espíritu de conquista que llevó al descubrimiento del Nuevo Continente.

El conocimiento que hoy en día podemos tener de la Biblioteca Hernandina se basa fundamentalmente en algunas pocas fuentes documentales de gran importancia como el testamento de 
Hernando Colón, el Memorial que dirigió a Carlos V en 1537 o la Memoria de las obras y libros de Hernando Colón escrita por el bachiller Juan Pérez; junto a ello están también los propios repertorios de la biblioteca y el tercio de los libros conservados hoy en la Biblioteca Colombina, en Sevilla, un material todo él consultado por diversos estudiosos y que ha servido para ir poco a poco descubriendo esta impresionante biblioteca en su verdadera magnitud. Una obra importante para llevar a cabo esta tarea es el voluminoso Catálogo concordado de la Biblioteca Hernando Colón (1993-1995), publicado por Tomás Marín Martínez, José Manuel Ruiz Asencio y Klaus Wagner; y entre algunos estudios reseñables de la Biblioteca Hernandina y de Hernando Colón se encuentra la obra de Henry Harrisse (1872, 1887), la de Andrés A. Esteban Romero (1939) o la de los ya mencionados Marín Martínez (1970) y Klaus Wagner (1992, 2000), aunque probablemente la investigación más completa sobre las múltiples facetas de Hernando Colón, y desde luego la mejor contextualizada, es la que ha llevada a cabo recientemente el profesor Edward Wilson-Lee (2019), quien ha sabido reivindicar la importancia de este bibliófilo y erudito más allá de los círculos especializados (1).

Nuestro propósito en el presente trabajo es contribuir a difundir los estudios sobre Hernando Colón. Lo que se pretende aquí, principalmente, es considerar la organización interna de su biblioteca y reconstruir parte de su orientación y sentido a partir de ciertos elementos filosóficos que son perceptibles en ella. Más en concreto se intentará mostrar los hilos básicos de su sistema de catalogación buscando relacionar sus recursos bibliográficos con ideas, a fin de evidenciar que la creación de esta biblioteca no es el resultado de una simple actividad de recolección, sino una obra del pensamiento que refleja intereses de conocimiento y una filosofía de fondo que hunde sus raíces en presupuestos centrales del Renacimiento. Ya desde el siglo XV comenzó a fraguarse una cosmovisión coherente y acorde a un ideal de universalidad que de algún modo Hernando Colón contribuirá a expandir, y uno de nuestros intereses precisamente es encontrar vínculos entre su biblioteca y este ideal. Además de esto, queremos darle importancia también a la Biblioteca Hernandina pudiendo situarla dentro de una perspectiva de historia de los sistemas de clasificación bibliográfica o documental, en particular relacionándolo con el pensamiento utópico de Francis Bacon y la obra de Paul Otlet.

\section{Los repertorios de la Biblioteca Hernandina}

A diferencia de otras bibliotecas privadas del Renacimiento, la Biblioteca Hernandina destaca no sólo por sus dimensiones y por su verdadera pretensión de universalidad, sino por contar con un sistema de organización de sus fondos bibliográficos muy funcional y novedoso. Los recursos de catalogación de esta biblioteca crean una estructura compleja a partir de un conjunto de repertorios bibliográficos interrelacionados, superando por ello a los catálogos convencionales, reducidos fundamentalmente a inventariar o clasificar de un modo muy general una colección de libros. Los repertorios de la Biblioteca Hernandina eran bastante diversos, con uno incluso dedicado a ordenar grabados o estampas, aunque concretamente los que mejor definen el sistema de catalogación de esta biblioteca son los que presentamos a continuación, dedicados cada uno de ellos a registrar y organizar los mismos libros pero siguiendo criterios clasificatorios distintos entre sí.

Libro de los Epítomes. De todos los repertorios, seguramente este sea el que forma la obra más singular e interesante, consistiendo en una colección de epítomes; es decir, resúmenes, sumarios o síntesis de una enorme cantidad de libros de los que se ha intentado extraer sus contenidos e identificar cuáles son sus argumentos principales (Figura 1). Ciertamente, Hernando Colón se sirvió de un recurso de comprensión textual muy utilizado en el Medievo por hombres como Isidoro de Sevilla, si bien es cierto que el manejo que en este libro se hace de los epítomes es acometido a una gran escala, habiéndose sintetizado al menos unas 2.000 obras, lo que podemos constatar por el volumen recién aparecido en la Universidad de Copenhague (Colón, 1522-1537). Este repertorio está formado concretamente por una sucesión de epítomes enumerados, ocupando por lo general cada uno de ellos media página, aunque en ocasiones son de mucha más extensión. Normalmente en el epítome se indica el nombre del autor o el título de la obra que se resume; y llama la atención que, en algunos casos, se añade otro número que parece ser que remitía al Índice Numeral (Marín Martínez, 1970, p. 375), otro repertorio al que nos referiremos. El Libro de los Epítomes servía así pues para dar una descripción interna de las obras de la biblioteca, rescatar sus ideas; propiamente dicho era un compendio de libros, cuyo principal valor reside en haber sido convertido por Hernando Colón en una herramienta bibliográfica al servicio de la organización bibliotecaria. 


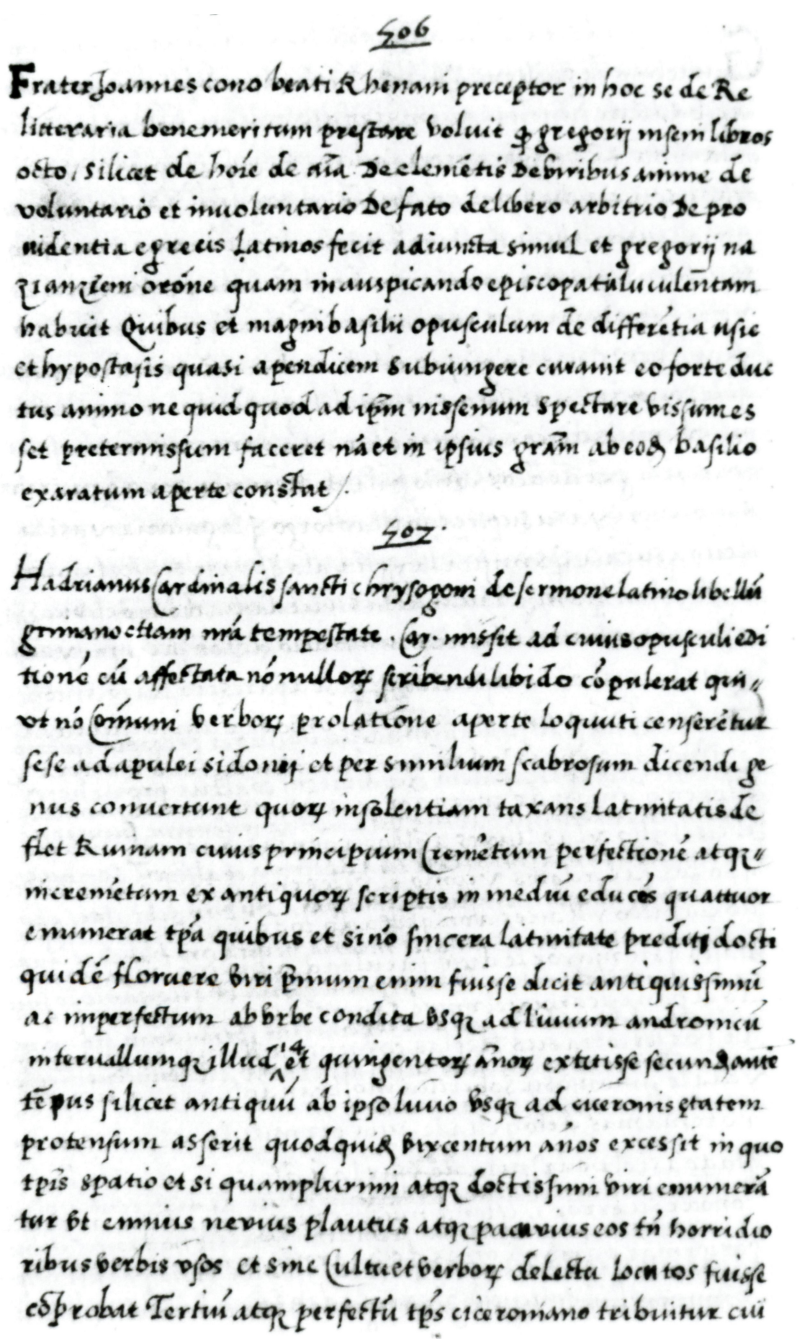

Figura 1. Epítomes 506 y 507 (Lib. Epít., f. 109v).

Libro de las Materias. Este otro repertorio, más que una descripción sintética de los libros, era una especie de colección de proposiciones que expresan de manera escueta y concisa sus ideas. Estas proposiciones o frases daban noticia de la materia de la que trataba un libro, especificándose en ella al final el autor, de conocerse, y el título. Así, por ejemplo, una proposición del Libro de las Materias como la siguiente (Lib. Mat. II, f. 28 r., cit. en Marín Martínez, 1970, p. 416):

Religionis quam tranquillus sit status et que sint pericula eiusdem, difuse docet Mapheus Vegius in libro de perseverancia religionis

nos informaría de que esta obra del humanista Mapheus Vegius versa sobre la tranquilidad del estado religioso y sus peligros. Algo que resulta interesante de este repertorio es que reordena miles de pensamientos bajo una misma fórmula (ibid.), organizando así con claridad multitud de temas y pudiendo remitirlos directamente a los libros de la biblioteca en los que se trataban. Las proposiciones de este repertorio estaban ordenadas alfabéticamente, pero cabe destacar además que, en la versión conservada, a estas proposiciones se les añade unos rectángulos vacíos que al parecer iban a remitir a otros libros sobre el mismo tema (ibid., p. 417 y 418), pudiendo agrupar así obras con semejanza temática. En términos documentales, queremos destacar que uno de los rasgos lingüísticos de este repertorio es que tiende a usar un lenguaje partiendo de palabras convencionales en vez de buscar construir un lenguaje artificial (Wilson-Lee, 2019, p.356), apelando al valor pragmático de las palabras y rechazando por lo tanto un criterio de clasificación basado en un control de vocabulario. Otro aspecto de interés en este repertorio es que, según el bachiller Juan Pérez, la intención de Hernando Colón era recortar cada una de las proposiciones en tiras o "papelejos" para reordenarlos luego (Memoria, 7, f. 10r r.), y esto nos hace pensar que Hernando Colón podría estar ideando ya una especie de sistema de fichas, lo que habría supuesto un claro precedente del catálogo de materias.

Índice General Alfabético (Abecedarium B). La función de este repertorio es en gran medida complementar y hacer prácticos los otros dos anteriores: aquellos describían los contenidos de los libros y especificaban la materia de la que trataban, pero no permitían organizar la colección, imprimir en ella un orden, pues para esto era necesario crear un índice que sirviera para localizar fácilmente los libros. Este repertorio era el más completo de todos, registrándose en él los más de 15.000 libros de la biblioteca (Marín Martínez, 1970, p. 486). Consistía, concretamente, en un índice de autores y títulos ordenados alfabéticamente, aunque incorporaba además otra información significativa que ayudaba a diferenciar cada asiento bibliográfico. Además de especificar autor - de conocerse- y el título, a menudo se incluía el incipit, y en todos ellos se añadía la signatura topográfica. De todos modos, uno de los aspectos más interesantes de este repertorio es que en muchos de los asientos se indicaba el lugar y la fecha de publicación; y junto a ello, en no pocos casos, también se especificaban los correspondientes números que la obra tenía en el Libro de las Materias y en el Libro de los Epítomes (ibid., p. 487-491). Así pues, por ejemplo, sabemos que los dos ejemplares de los Adagia de Erasmo que había en la biblioteca y cuyas signaturas topográficas eran 2466 y 12910 fueron publicados en Basilea (Ba.) en 1533, que su número en el Libro de las Materias era el 3434 y en el Libro de los Epítomes el 3130 (Memoria, 9, f. 17 r.). Toda esta información ayudaba a que los otros repertorios pudieran ser fácilmente manejados, haciendo de este índice una de las obras 
claves dentro del sistema de organización de la biblioteca (2).

Índice Numeral de los libros (Registrum B). Mientras que el Abecedarium organizaba los fondos bibliográficos alfabéticamente, este repertorio lo hacía siguiendo un orden cardinal, enumerando los libros conforme a su posición determinada en la biblioteca. Generalmente, se señalaba el título y el incipit, pero junto a esto se añadía también una descripción de los libros de carácter formal, atendiendo a aspectos externos tales como la división de la obra, el idioma, su forma estilística e informando además de la impresión y de datos concernientes a la compra (Marín Martínez, 1970, p. 564 y 565). La función principal del $R e-$ gistrum era establecer equivalencias entre la signatura topográfica y el Abecedarium, y llama la atención que esto es algo que en el repertorio -a continuación de la parte de las descripciones- se llegaba a especificar ya sólo con números, estableciendo correspondencias entre las cifras de ambos índices (ibid., p. 582). Este repertorio servía en primer lugar, por lo tanto, para hacer más manejable el Abecedarium y para localizar con facilidad los libros, pero paralelamente ayudaba a complementar la información descriptiva de los libros y planteaba ya la posibilidad de organizar la catalogación mediante guarismos.

Índice de Autores y Ciencias. El conjunto de los repertorios elaborados por Hernando Colón suponía una verdadera herramienta de organización bibliotecaria, aunque resultaba deficiente sin un esquema del conocimiento al que remitir cada libro, creando para ello tardíamente este nuevo repertorio. A pesar de quedar muy incompleto, el Índice de Autores y Ciencias nos permite reconstruir una clasificación que nos informa de los ámbitos de conocimiento que la biblioteca alberga. Los asientos bibliográficos en este repertorio suelen expresarse indicando el título y el autor de la obra, de conocerse; una palabra abreviada que indicaba la ciencia en la que se enmarcaba; la signatura topográfica o número del Índice Numeral y una cifra, a veces, que se sospecha que remitía a una clasificación de grandes grupos temáticos con la que se ordenaba la biblioteca (ibid., p. 658). La clave de este repertorio se encontraba, ciertamente, en aquella palabra abreviada que remetía a una disciplina ("medi." para referirse a medicina, por ejemplo). El número de disciplinas consideradas era muy amplio, llegando a la treintena (ibid., p. 656). Comprendía las artes liberales y mecánicas, las divisiones de la filosofía, el derecho, la medicina y también otras artes y ciencia que reflejan los intereses humanísticos y científicos de Hernando Colón. Todo el saber de su tiempo se encontraba recogido en las distintas disciplinas que forman esta clasificación, haciendo honor a una biblioteca que pretendía abarcar todo el conocimiento existente. Destacamos, además, que las distintas disciplinas aparecían como ciencias generales en las que muchas veces se especificaba una parte especial de ella (theologia moralis hispanica; historia gallica) (ibid.), pudiendo pues combinar clases por semejanzas, al modo de las actuales taxonomías. Es importante saber que la clasificación presupuesta en este repertorio no fue creada según un orden rígido; dicho orden no estaba basado en la subordinación de unas clases a otras, dando más bien importancia a cada una de ellas, un hecho que es de capital importancia al superarse así las restricciones doctrinales heredadas del Medievo.

\section{Aspectos filosóficos subyacentes}

Toda la empresa hernandina está orientada por un claro propósito de universalidad que en buena medida es típico del Renacimiento, aunque toma una dirección que es distinta a la del Renacimiento italiano. En los años que vivió en Roma, Hernando Colón conocería algunas de las colecciones de libros más importantes de su tiempo, si bien es verdad que sus expectativas no encajaban con el modelo de biblioteca perfecta como el que propusiera Tommaso Parentucelli, cuyo plan exigía descartar obras menores o de poco prestigio para crear una colección selecta y mayormente sólo con obras en latín y griego (WilsonLee, 2019, p. 203). La Biblioteca Hernandina se formaría en cambio sin seguir unas pautas ortodoxas, descartándose el canon de armonía y orden de los italianos, y sin reducir sus intereses no teológicos a los temas humanísticos, la matemática o a la idealidad platónica. Wilson-Lee ha destacado de hecho que Hernando Colón descubrirá en el norte de Europa un mundo más complejo y cargado de abundancia que se alejaba del clasicismo de Roma (ibid., p. 276), lo que es muy probable que influyera bastante en su modo de entender el conocimiento. En la ciudad de Lovaina, en 1520, conocería a Erasmo, con el que compartirá la pasión por los libros y una idea de cristiandad como cultura universal con la que poder ligar a las distintas naciones. Pensamos, no obstante, que tampoco es posible hablar sin embargo de un claro erasmismo en Hernando Colón teniendo en cuenta que para este último aquella universalidad no debía quedar articulada desde el latín, interesándose mucho —como podemos constatar por los libros de su colección- por obras en lenguas vernáculas e incluso no cristianas como el árabe. Esta apertura más allá de las fronteras latinas aproxima a Hernando Colón, y no poco, a un pensador como Ramon Llull, al que sabemos que llegaría a leer bastante (ibid., p. 181), registrándose una treintena de libros de 
este sabio en el Abecedarium (De la Concha Delgado, 1992, p.328). Algo que caracteriza fundamentalmente a Llull es el hecho de haber sido un conciliador de culturas intentando fomentar el diálogo entre religiones. A través de obras suyas como las distintas versiones de sus Ars magna, el filósofo mallorquín idearía procedimientos lógicos para encontrar los elementos comunes de las grandes religiones, partiendo de la idea de que existe una racionalidad de las creencias. En esta misma dirección, hemos de saber que Hernando Colón adquiriría libros de distintas lenguas y credos; y desde luego es del todo reseñable que uno de sus colaboradores más estrechos llegara a ser el humanista Clenardus, quien sería conocido precisamente por manejar lenguas como el hebreo y el árabe, así como por su vasta erudición en concreto sobre el Corán (Chauvin et Roersch, 1900-1901, p. 42).

De todas maneras, en el proyecto bibliotecario de Hernando Colón resulta posible rastrear también las ideas filosóficas generadas apenas un siglo atrás por Nicolás de Cusa. Este filósofo destacaba por haber introducido la idea de infinito en la reflexión sobre el universo antes que Giordano Bruno. En su obra De docta ignorantia (1440), donde se expone una teodicea y unas ideas sobre el cosmos que habrán de tener mucha importancia en la modernidad, el Cusano concebiría a la divinidad como infinito, y por lo tanto como algo inconmensurable, no pudiendo conocerse más que mediante conjetura. Tal idea le servirá de partida para establecer una oposición radical entre el cosmos y el ser absoluto, entre la finitud y la infinitud divina, lo que permite abrir una vía de estudio y de comprensión del cosmos desde sus propias características empíricas. Para salvar esta brecha entre dos realidades distintas, sin embargo, el Cusano entenderá que hay un nexo que permite establecer un vínculo entre el mundo y su creador, concibiendo que Dios se contrae en el universo siendo "la infinitud contracta" (II, 4). Esta idea de contracción (contractio) será sumamente relevante en la filosofía posterior, llegando de algún modo hasta Hegel, pues permite salvar al universo de una concepción puramente materialista y concederle una procedencia divina que lo liga con la infinitud. Es importante saber que para este filósofo el universo lo forman cosas particulares, de ahí que Dios se contraiga entonces en el universo no de un modo general, sino en cada una de aquellas cosas; y algo que destaca, a su vez, es que el universo por lo tanto no será tomado como una masa homogénea, sino que en él existe la diversidad, y por eso se nos dirá que todas las cosas son en grados diversos (II, 5). En general, con esta filosofía Nicolás de Cusa vino a difundir una visión de universo ilimitado que contrastaba con la de la Edad Media, sobre todo por afirmar que "la máquina del mundo tendrá el centro en cualquier parte" (II, 12), introduciendo la posibilidad de un orden relativo en el universo al no existir un centro físico privilegiado.

Esta imagen de un universo ilimitado guarda muchas semejanzas con el propósito hernandino de crear una biblioteca cuya universalidad, en gran medida, debe asociarse a su expansión fuera de todo límite. De algún modo en esta biblioteca se contraía también una infinitud que en este caso correspondía a la totalidad del saber, constituyéndose verdaderamente como el universo del conocimiento. Al igual que en el cosmos del $\mathrm{Cu}$ sano, cada parte de este universo tendría un valor propio al contraerse en él la divinidad, lo que en la Biblioteca Hernandina se refleja concretamente en la importancia que en ella se daba hasta a la menor de las obras sin conceder tanta preferencia, en cambio, a los libros canónicos o a los comúnmente más prestigiados, de ahí que Hernando Colón descartara incluso adquirir antes obras mayores que pequeñas (Colón, 1872, p. 211). La pérdida de un centro privilegiado en esta biblioteca-cosmos rechaza por lo tanto la idea de una ordenación jerárquica, y prueba de ello es la tabla de las ciencias que maneja para organizar su colección, que como hemos visto ni es una clasificación rigurosa ni impone una estructura de orden determinado. Cada ejemplar de la biblioteca aparece más bien como una realidad propia y singular, dándose acogida a toda clase de temas, formatos, distintos estilos e idiomas, para componer así una colección formada por grados diversos y que sea un compendio de la multiplicidad del universo más allá de los límites fijados por el modelo unitario y dogmático católico (3). Precisemos, además, que el ideal de Nicolás de Cusa estaría presente en Hernando Colón al procurar ajustar no obstante su biblioteca a la medida del hombre, puesto que no parece que se intentara reproducir el orden del conocimiento como si se tratara de una pauta externa, sino disponerlo más bien desde el pensamiento. Para Nicolás de Cusa captar la multiplicidad del cosmos exigía hacerlo desde las abstracciones de la mente y no desde las esencias de las cosas (Cassirer, 2004, p. 77), implicando así de lleno de un modo activo al alma humana. De tal forma se podía aspirar a una conciliación entre lo uno y lo múltiple, un ideal perseguido durante todo el Renacimiento y que pensamos que Hernando Colón se encargará de realizar en un proyecto bibliotecario que servía para unificar la complejidad del conocimiento en un todo ordenado que es capaz de respetar las diferencias entre las distintas ramas del saber y, por encima de todo, de no asfixiar al alma humana en la inmensidad de un universo sin límites por tratarse de una empresa que 
procura volver a los hombres más sabios facilitándoles las ciencias "en más breve tiempo y a menos costa" con la voluntad siempre de que el conocimiento pudiera reducirse en extensión y servir para "regir el mundo": tal parece que fuera el deseo de Hernando Colón, como bien señala el bachiller Juan Pérez (Memoria, 4, f. 4 v.).

Quisiéramos advertir también que el fondo filosófico rastreable en la empresa hernandina no se agota sin embargo en referencias que provienen de las letras o del pensamiento, sino que también, en particular, encontramos elementos de interés en fenómenos tales como la cartografía, a la que el hijo del célebre navegante genovés estaría muy ligado a lo largo de su vida. Como sucede con otras mentes polifacéticas del Renacimiento, la falta de una filosofía programática en este hombre no nos permite comprender su obra desde una perspectiva meramente teórica, pudiendo descubrir más bien aspectos sobre su visión de la organización del conocimiento en conexión con la práctica de creación de mapas. Descripción y cosmografía de España o Itinerarios (1517-1523) es un buen ejemplo de los intereses cartográficos de Hernando Colón, una obra en la que trataría de describir con gran detalle poblaciones de España y sus entornos, recopilando multitud de noticias recogidas por informantes que enviaba a todas las partes del territorio (Memoria, 1, f. 1 r.). Este procedimiento de trabajo puede verse reflejado en el modo en el que Hernando Colón ampliaba su biblioteca, enviando cada seis años a sus emisarios para que recorrieran las rutas comerciales de los libros (Wilson-Lee, 2019, p. 414), pero también en la creación misma de sus detallados repertorios bibliográficos, verdaderos arcas de información; aunque en cualquier caso, las repercusiones de la tarea cartográfica aparecen sobre todo en el hecho mismo de buscar elaborar todo un sistema de organización bibliotecaria que pudiera representar el universo del conocimiento.

Aun de un modo figurado, pensamos, en concreto, que es posible trazar un paralelismo con algunos de los elementos propios de los grandes planisferios utilizados desde finales de la Edad Media, como por ejemplo el de la Geographia de Ptolomeo reproducido por Nicolaus Germanus (1482). La Biblioteca Hernandina cuenta con una división de las regiones del conocimiento al igual que Ptolomeo fijaba las latitudes y longitudes para organizar geométricamente el espacio, aunque en el caso de la biblioteca aplicando una tabla de las ciencias para ordenar los libros en vez de diferenciar regiones por climas. Otro paralelismo con la cartografía de su tiempo podemos encontrarlo en II mappamondo di Fra Mauro (ca. 1450), uno de los grandes mapas de este tiempo y al que caracteriza que incluye, junto a su riqueza en el detalle geográfico, una descripción verbal de los territorios, de los mares e incluso de aspectos astronómicos, lo que en gran medida podría asemejarse bastante a las descripciones de la Biblioteca Hernandina recogidas en el Libro de los Epítomes. Una diferencia fundamental que encontramos en cambio en la creación de Hernando Colón es que, a diferencia del mapa de Fra Mauro, su visión del mundo llega a acoger el Nuevo Continente abarcando así todo el universo del conocimiento; y pensamos también que, frente al aspecto visual y narrativo del mapa de Fra Mauro, el espíritu cartográfico de Hernando Colón procura incluir en su sistema bibliotecario una orientación para facilitar la navegación por el vasto océano de libros que acumula, pudiendo en este caso encontrar semejanzas más bien con otro modo de hacer cartografía como el de los mapas portulanos. Estos mapas, utilizados y elaborados entre muchos otros por Cristóbal Colón, fueron definidos para facilitar la navegación marítima, los cuales incluían toda una compleja retícula marcando direcciones a partir de la rosa de los vientos para definir rumbos, un procedimiento que no era muy distinto, en el fondo, a la red de conexiones creadas por la catalogación de la Biblioteca Hernandina.

\section{Los inicios modernos de la actividad documental}

Uno de los rasgos principales de la Biblioteca Hernandina es que almacena y registra material escrito e imágenes que proceden de todas las partes del mundo, funcionando como una sede organizada que centraliza información. Ya sólo por esto es posible encontrar muchas semejanzas con un proyecto de clasificación de documentos como el que creara Paul Otlet a finales del siglo XIX, en donde pensamos que ciertamente se reproducen bastantes aspectos esenciales de la tarea llevada a cabo por Hernando Colón. Existen, a decir verdad, muchos elementos comunes entre ambos proyectos pese a que su filosofía de fondo difiera; la actividad de este último es la propia de un humanista y polímata del Renacimiento mientras que la de Otlet es la de una mente en buena medida burocratizada e inspirada por los ideales del positivismo, aunque estas diferencias no impiden que sus obras compartan un mismo espíritu que coincide en aspirar a la universalidad y crear los recursos necesarios para organizar grandes masas de información con eficacia y valiéndose de procedimientos novedosos. Es significativo, por ejemplo, que la empresa hernandina, además de contar con aquellos emisarios que adquirían libros viajando por Europa, tuviera a su disposición colaboradores 
dedicados a sintetizar y clasificar las obras de su biblioteca -propiamente dicho estos serían los llamados "sumistas" (Memoria, 4, f. 4 v. y 5 r.)-; una tarea basada en equipos de trabajo y que caracterizará igualmente al Instituto Internacional de Bibliografía (IIB) siglos después. La Biblioteca Hernandina y el IIB pueden llegar a concebirse en realidad como organizaciones, confiándose en la colaboración de otras personas al tenerse consciencia de la magnitud de estas obras; y en ambos casos cabe decir que tales organizaciones llegan a tener un alcance universal no sólo al intentar crear un registro completo de todo el saber humano, sino al sobrepasar fronteras de facto y no agotarse en expectativas nacionales, un rasgo en concreto que, a nuestro juicio, vincula más a Otlet con Hernando Colón que con la Enciclopedia francesa.

En términos directamente relacionados con los recursos técnicos, podemos decir que la Biblioteca Hernandina anticipa en muchos aspectos la ingeniería documental del IIB. El propósito de Otlet de construir un Repertorio Bibliográfico Universal (RBU) a partir de un conjunto de repertorios distintos (IIB, 1905, p. 25 y ss.) hemos visto que es una idea que aparece ya con Hernando Colón, quien distingue tipos de registros para organizar información con criterios bibliográficos diferentes. Así mismo, en Hernando Colón aparece ya prefigurado un sistema de clasificación complejo que combina la descripción formal de los libros con la de sus contenidos, e incluso intenta normalizar tales descripciones mediante guarismos y signos con cierto carácter simbólico, un propósito que revela ya las intenciones básicas de querer crear un sistema de clasificación para organizar una biblioteca universal, no difiriendo en sus expectativas con las del ideario de la Clasificación Decimal Universal. El célebre sistema de fichas del RBU pudo haber sido también un recurso concebido al menos, aunque no desarrollado, por el talento clasificador de Hernando Colón; aunque seguramente ninguna otra cosa vincularía más la Biblioteca Hernandina con el proyecto del IIB como el hecho de no limitarse sólo a la adquisición de libros, sino recopilar también panfletos, cartas o cualquier clase de escrito así como imágenes, anticipándose antes que en Otlet el concepto mismo de documento y la organización documental.

La pretensión de rastrear información de todo el mundo con vistas a crear una sociedad del conocimiento es un ideal que cobra forma en la modernidad principalmente a partir de la obra New Atlantis (1626) de Francis Bacon, aunque resulta muy interesante apreciar cómo la Biblioteca Hernandina reproduce ya en esencia, y un siglo antes, las ideas básicas de la utopía baconiana.
Imaginando la isla de Bensalem, el filósofo inglés había concebido una civilización técnica y culturalmente muy avanzada, proyectando en ella un ideal de sociedad regida por una institución de sabios a la que llamará la Casa de Salomón. Cada cierto tiempo, algunos de sus miembros emprendían viajes marítimos para recaudar información de lo que sucedía en otros países lejanos, preocupándose sobre todo de asuntos concernientes a ciencias, artes o descubrimientos y trayendo libros y todo tipo de instrumentos no para acumular riquezas, sino para obtener conocimiento (Bacon, 2020, p. 40 y 41). La Casa de Salomón se presenta como toda una estructura institucional a servicio del conocimiento y basada fuertemente en la experimentación, disponiendo de un gran número de laboratorios a fin de modificar la naturaleza y fomentar el desarrollo de la ciencia y de la técnica. Destaca el hecho de que esta sociedad contaba con distintos niveles de organización, definiendo incluso clases dentro de sus miembros según las funciones que habían de desempeñar, como por ejemplo los Comerciantes de la luz, que eran los encargados de traer libros; los Hombres del misterio, los que coleccionaban experimentos; o los Inoculadores, que eran los que ponían en funcionamiento los experimentos y los divulgaban (ibid., p. 73 y ss.).

Algo que nos interesa especialmente advertir es que esta construcción utópica de Bacon anticipa no poco la tarea documental, como ya han sabido ver algunos estudiosos (Reyes Ortiz et al., 1981). El espacio del saber que forma la Casa de Salomón no es, en realidad, muy distinto tampoco al ideado por Hernando Colón en su biblioteca, encontrándonos en él también el propósito de adquirir conocimientos de todas partes e involucrando además una organización bien desarrollada, como viéramos. A nuestro juicio, la idea de crear un sistema complejo de recogida, transformación y difusión de información es una pretensión común que vincula en general la obra de Hernando Colón, Bacon y Otlet. Podemos encontrar una relación entre ellos en la medida en la que sus proyectos son tres intentos utópicos de fundar una sede mundial del conocimiento a partir de recursos institucionales bien reglados y bajo un criterio de practicidad. Todos ellos buscan formar de algún modo una red de tráfico de información e involucrar a equipos de trabajo para tal fin, si bien es cierto que la conexión más fuerte entre la Biblioteca Hernandina, la Casa de Salomón y el IIB radica más bien en su tendencia compartida a alcanzar un ideal de saber relacionado en el fondo con el augmentis scientiarum promovido por el propio Bacon. Aun usando medios distintos y estrategias filosóficas que tampoco son completamente semejantes ni compati- 
bles, en cualquier caso, estas tres mentes utópicas sí que están buscando asentar a su modo las mejores vías para facilitar el acceso a la información en beneficio del saber y el perfeccionamiento humano. Así mismo, intentan poner en marcha el ejercicio de unas prácticas de organización del conocimiento verdaderamente universales y que con Otlet conducirán a una difusión de la información todavía irrealizada por sus presentes, aun habiéndola anhelado, lo que nos permite a fin de cuentas encontrar cierta continuidad en sus proyectos, pudiendo tratar con perspectiva histórica algunos de los momentos más relevantes en el desarrollo de los sistemas de clasificación bibliográfica o documental.

\section{Conclusiones}

La organización interna de la Biblioteca Hernandina a partir de un conjunto de repertorios es un recurso que ha demostrado tener mucha eficacia para clasificar una gran cantidad de libros, panfletos o imágenes. Concretamente los repertorios bibliográficos tales como el Libro de los Epítomes, el Libro de las Materias, el Abecedarium y el Registrum permiten diferenciar distintos aspectos de un mismo documento, enriqueciendo la práctica de catalogación, y entre sus características principales está la capacidad de clasificar considerando contenidos y especificando los temas de los objetos que se clasifican, a lo que hay que sumar las ventajas añadidas con el Índice de Autores y Ciencias, con el que se consigue incluso enmarcar la colección de libros dentro de una estructura general del conocimiento. Distinguiéndose de las bibliotecas privadas italianas, hemos visto que la biblioteca de Hernando Colón ofrece una apertura de fronteras que puede remitir a la aspiración de cristiandad defendida por Erasmo; aunque el interés en otras culturas y lenguas la aproxima bastante más al propósito integrador del diálogo interreligioso perseguido por Ramon Llull. A pesar de ello, hemos querido mostrar que la visión de universalidad de la Biblioteca Hernandina encaja bien con el ideal de universo de Nicolás de Cusa, desde donde es posible hacer una interpretación del afán de abarcar el conocimiento como un cosmos, dando importancia a cada obra por formar una parte integrante y esencial en el conocimiento aun no siendo canónica; además, la filosofía del Cusano, que pierde intencionadamente la centralidad del cosmos, es seguramente una de las mejores formas con las que pudiera leerse el propósito hernandino de no organizar una biblioteca desde una orientación religiosa o ideológica determinada, relacionándola así con una idea de mucha relevancia en la astronomía y la filosofía de la modernidad. Hemos señalado, además, que el proyecto de Hernando Colón tiende puentes con el ideal utópico de Bacon y con la obra de Otlet por su concepción de universalidad y por intentar crear un espacio donde poder albergar todo el conocimiento humano recogiendo, transformando y difundiendo información, tres funciones básicas de la tarea documental. En este sentido, Hernando Colón iniciaría en gran medida ya la tarea documental concibiendo una forma de organizar el conocimiento a gran escala que se preserva en sus líneas básicas en nuestros días. Su obra, sin embargo, pensamos que no pude ser entendida sólo desde los intereses más estrechos de la erudición y conforme a un simple impulso de acumulación de saber, pues se refleja en ella más bien una orientación que, como hemos visto, guarda parentesco con algunos de los caminos abiertos por el pensamiento de su tiempo, apareciendo, pues, como un gran proyecto de organización del conocimiento que revela un ideal de armonía entre el individuo y el cosmos. Este ideal en Hernando Colón puede preservarse aun la magnitud del universo del conocimiento en tanto que los medios que se utilizan para representarlo, como sucede con los mapas de este tiempo, no dejan de descubrirnos nunca una medida humana, poniendo así pues a nuestro alcance y a nuestro servicio el dominio entero de las ideas producidas por nuestra especie para crear verdaderos sabios con capacidad de regir el mundo.

\section{Notas}

(1) De este mismo autor, y en colaboración con el profesor José $M^{a}$ Pérez Fernández, cabe destacar también el trabajo titulado Hernando Colón's New World of Books. Toward a Cartography of Knowledge, publicado a principios de este año. Otros estudios de interés en nuestra lengua serían Memoria de D. Fernando Colón (1893) de José Gestoso y Don Hernando Colón. Su vida, su biblioteca, sus obras (1945), de Torre Revello.

(2) Advirtamos que este repertorio contaba a su vez con otros recursos adicionales para representar los contenidos de los libros. Además de números, nos encontramos con símbolos para indicar tamaños de los libros, o si eran traducciones, o si en él se defendía a cierto autor o se lo atacaba, etc., creando con ello un lenguaje pictográfico. Como indica Wilson-Lee (2019, p.306), este lenguaje recuerda en su forma al alfabeto que Tomás Moro había incluido en la segunda edición de su Utopia. La especificación detallada de estos símbolos podemos verla en Memoria, 8, f. 11r-15r.

(3) Esto no quita que Hernando Colón fuera fiel a la Iglesia Católica Romana, aunque lo decisivo está en que sus convicciones no llegan a repercutir en la organización de su biblioteca. Como bien nos indica Klaus Wagner (2000, p.68), algo así explica por qué Hernando Colón atesoraría una importante colección de obras que versan sobre la Reforma. 


\section{Referencias}

Bacon, F. (2020). La Nueva Atlántida. Lima: Municipalidad de Lima.

Cassirer, E. (2004). El problema del conocimiento I. México: Fondo de Cultura Económica.

Chauvin, V.; Roersch, A. (1900-1901). Étude sur la vie et les travaux de Nicolas Clénard. // Académie royale des sciences, des lettres et des beaux-arts de Belgique (ed.). Mémoires couronnés et autres mémoires, LX. Bruxelles: Imprimeur Royale des sciences, des lettres et des beauxarts de Belgique, 5-202.

Colón, H. (1522-1537). Libro de los Epítomes. [Manuscrito]. [AM 377 fol.]. http://digitalesamlinger.hum.ku.dk/Home/ Samlingerne/25258

Colón, H. (1872). Testament de Fernand Colomb. // Harrisse, H. Fernand Colomb, sa vie, ses œuvres: Essai critique par l'auteur de la Bibliotheca Americana Vetustissima. Paris: Librairie Tross.

De la Concha Delgado, F. G. (1992). Manuscritos Lulianos de la Biblioteca colombina de Sevilla. BSAL, 48, 327-338.

Esteban Romero, A. A. (1939). Don Fernando Colón: Su personalidad literaria, repertorios bibliográficos y manuscritos. Sevilla: Publicaciones Diocesanas.

Harrisse, H. (1872). Fernand Colomb, sa vie, ses œuvres. Essai critique par l'auteur de la Bibliotheca Americana Vetustissima. Paris: Librairie Tross.

Harrisse, H. (1887). Excerpta Colombiniana : Bibliographie de quatre cents pièces gothiques françaises, italiennes et latines du commencement du XVle siècle non décrites jusqu'ici précédée d'une histoire de la Bibliothèque Colombine et de son fondateur. Paris: $\mathrm{H}$. Welter.
IIB (1905). Manuel abrégé du Répertoire Bibliographique Universel: Organisation, travaux, méthodes, tables abrégés de classification. Bruxelles, Paris et Zurich: Institut International de Bibliographie.

Marín Martínez, T. (1970). "Memoria de las obras y libros de Hernando Colón" del bachiller Juan Pérez. Madrid: Cátedra de Paleografía y Diplomática.

Marín Martínez, T.; Ruiz Asensio, J. M.; Wagner, K. (19931995). Catálogo concordado de la biblioteca de Hernando Colón. Madrid: Fundación Mapfre América; Sevilla: Cabildo de la Catedral.

Nicolás de Cusa (1973). La docta ignorancia. Madrid: Aguilar.

Pérez, J. (1970). Memoria de las obras y libros de Don Hernando Colón. // Marín Martínez, T. (ed.). Memoria de las obras y libros de Hernando Colón" del bachiller Juan Pérez. Madrid: Cátedra de Paleografía y Diplomática, 4776.

Reyes Ortiz, I.; Serra, R.; Torrejón, D. (1981). Esbozos de la ciencia documental en la literatura utópica. Documentación de las ciencias de la información, 5, 261-269.

Wagner, K. (1992). La biblioteca colombina en tiempos de Hernando Colón. Historia. Instituciones. Documentos, 19, 485-495.

Wagner, K. (2000). La locura de don Hernando Colón. Boletín de la Real academia Sevillana de Buenas Letras: Minervæ Bæticæ, 28, 63-79.

Wilson-Lee, E. (2019). La bibliothèque engloutie. La quête idéale du fils de Christophe Colomb. Paris: Paulsen.

Enviado: 2021-09-18. Aceptado: 2021-09-24. 
